\title{
Epidemiological Characteristics of Human Brucellosis in Shahin Dezh, Western Azarbaijan, Iran, 2008-2012
}

\author{
Farzad Maleki ${ }^{1}$; Hosein RafieManesh ${ }^{1}$; Abbas Abbasi-Ghahramanloo ${ }^{2}$; Naser Ghadimi ${ }^{1}$; \\ Ahmad Kousha ${ }^{3}$; Saeid Safiri ${ }^{1,4}$; \\ ${ }^{1}$ Department of Epidemiology and Biostatistics, School of Public Health, Tehran University of Medical Sciences, Tehran, IR Iran \\ ${ }^{2}$ Department of Epidemiology and Biostatistics, School of Public Health, Iran University of Medical Sciences, Tehran, IR Iran \\ ${ }^{3}$ Department of Health Educations and Promotion, Tabriz University of Medical Sciences, Tabriz, IR Iran \\ 4 Road Traffic Injury Research Center, Department of Statistics \& Epidemiology, Tabriz University of Medical Sciences, Tabriz, IR Iran \\ ${ }^{*}$ Corresponding author: Saeid Safiri, Road Traffic Injury Research Center, Department of Statistics and Epidemiology, Tabriz University of Medical Sciences, Tabriz, IR Iran. Tel: +98-9141005277, \\ E-mail:S-Safiri@razi.tums.ac.ir
}

Received: July 24, 2014; Revised: December 30, 2014; Accepted: January 13, 2015

\begin{abstract}
Background: Brucellosis is still one of the most challenging issues for health and the economy in many developing countries such as Iran. Objectives: This study investigated the epidemiological features of brucellosis in Shahin Dezh, Western Azarbaijan province, North West of Iran.

Patients and Methods: This study had across-sectional design and data was collected from private and public sectors over a five-year period (2008-2012). All cases were studied between years 2008 and 2012 in Shahin Dezh.

Results: In total, 492 cases of brucellosis were reported. The prevalence of brucellosis decreased from 152 cases/100000 inhabitants in 2008 to 97 cases/100000 inhabitants at the beginning of 2012. About 52.3\% of subjects were male, and most cases of brucellosis were aged 25-30 years. Eighty-one percent of subjects lived in rural areas. There was a statistically significant difference regarding contact with livestock between rural and urban areas (91.7\% vs. 68.8\%) (Pvalue $<0.001$ ). Raw milk was the most commonly consumed dairy product; consumed by $37 \%$ of cases. Finally, during winter and spring a high prevalence rate of brucellosis was reported.

Conclusions: Comprehensive health-related interventions need to empower communities at risk, especially young men and young and adult women in the Shahin Dezh County. Health education is needed to raise awareness of people in the studied area.
\end{abstract}

Keywords:Brucellosis; Epidemiology; Iran

\section{Background}

Brucellosis is one of the most common zoonotic infectious diseases (1), which is transmitted to humans through consumption of unpasteurized dairy products or through direct contact with infected animals, placentas or aborted fetuses. This bacterial disease causes a severely debilitating and disabling illness, with fever, sweating, fatigue, weight loss, headache, and joint pain persisting for weeks to months (2).

The importance of Brucellosis is not only due to its physical complications, it is also considered to be one of the biggest challenges for economic development in many countries such as Iran (3) due to patients being unable to perform their normal daily activities (2) and losses in animal production (4). Brucellosis is widespread in the world, and it isprevalent in countries of the Mediterranean basin, the near east, South America, and possibly Sub-Saharan Africa (3). The World Health Organization (WHO) has estimated that 500000 cases are reported worldwide annually, while this value is one-fifth of all cases $(5,6)$.

Brucellosis is an endemic disease in Iran, and its prevalence calculated by studies from Iran is 23.86 cases per
100000 individuals per year $(7,8)$. Prevalence rate of brucellosis in various parts of Iran varies from 0.73 to 141.60 per 100000 (7, 9,10). Western Azarbaijan province, with a prevalencerate of 71.4 per 100000 individuals, has been one of the most importantendemic areas of brucellosis in north of Iran (11). Despite the importance of the mentioned disease in this province, studies about its trend and correlations are rare.

\section{Objectives}

This study aimed to determine the epidemiological features of brucellosis in one of the most important counties of the Western Azarbaijan province, Shahin Dezh, during a five-year period.

\section{Patients and Methods}

\subsection{Study Design}

This study had a cross-sectional design and was conducted on all patients $(\mathrm{n}=492)$ with brucellosis, during a five-year period from 2008 to 2012.

Copyright (C) 2015, Infectious Diseases and Tropical Medicine Research Center. This is an open-access article distributed under the terms of the Creative Commons Attribution-NonCommercial 4.0 International License (http://creativecommons.org/licenses/by-nc/4.0/) which permits copy and redistribute the material just in noncommercial usages, provided the original work is properly cited. 


\subsection{Setting and Participants}

This study was done in the Shahin Dezh County. Shahin Dezh County is a county in the West Azarbaijan Province of Iran. The capital of the county is Shahin Dezh. At the 2006 census, the county's population was 89356 with 20911 families (Azarbaijani Turks being the majority). The county is subdivided into two districts; the Central District and Keshavarz District. The county has three cities: Shahin Dezh, Mahmudabad and Keshavarz.

Based on the national surveillance of brucellosis, the inclusion criteria were as follows, suspected clinical symptoms, Wright test titer of $>1 / 80$, positive Coombs-Wright's test or titer of 2-mercaptoethanol (ME) test $>1 / 40$, and having records at one of the health centers during the past five years as a new case, relapse or failure case. Data collection was done using a standard questionnaire in current use by the health surveillance system. These data included demographic and epidemiological information, which were collected from all of the state-related health centers and private clinics and laboratories within the Shahin Dezh County over a five-year period (20082012). It is important to note that, during the entire research, confidentiality was established and names of the subjects were not declared.

\subsection{Sampling, Sample Size and Statistical Analysis}

All of the identified subjects $(n=492)$ who had referred to the Shahin Dezh health center were included in the study using the health center's records. For analyzing the data Stata version 11 was used. In the descriptive statistics, means $( \pm S D)$ and frequencies were used for quantitative and qualitative variables, respectively. It is important to mention that, because the expected frequency in cells was not enough, multiple Fisher's exact test was used for analyzing the qualitative variables.

\section{Results}

In total, 492 affected cases with brucellosis symptoms whose disease had been confirmed by diagnostic tests were included in this study. Six and five individuals were failure and recurrent cases, respectively. According to the authors' estimations, the prevalence of brucellosis decreased from 152 cases/100000 inhabitants in 2008 to 97 cases/100000 inhabitants at the beginning of 2012. Meanwhile, the average prevalence of brucellosis was 102.86 / 100000 over the five-year period of the study in this province; $37.58 / 100000$ in the urban population and 172.83 /100000 in the rural population (Figure 1).

The subjects were aged two to 87 years. About $52.3 \%$ of the subjects were male. Eighty-one percent of subjects lived in rural areas. The prevalence of brucellosis was higher in younger age groups than older age groups. The median age of cases was 31 years; 28 years in males and 33 years in females. According to this study, most cases of brucellosis were aged $25-30$ years (10\%). The age distribu- tion was not significantly different between urban and rural areas (Pvalue $=0.426)$, Figure 2 .

The findings showed that housewives and students were more profoundly affected in both urban and rural groups (40.9\% and $20.4 \%$ in rural; $39.1 \%$ and $13.8 \%$ in urban, respectively). Meanwhile, the most common occupations among cases from urban areas were labor (9.7\%), rancher (6.5\%), and self-employment (6.5\%). Among rural cases, ranchers $(12.5 \%)$, and farmers (9.8\%) were more affected after housewives and students (Table 1).

There was a statistically significant difference regarding contact with livestock between cases from rural and urban areas (91.7\% vs. $68.8 \%$ ) (P value $<0.001$ ). Ninety-one percent of housewives in rural areas had contact with livestock, and this rate was $57.9 \%$ in urban areas. Direct contact with livestock was higher in rural students than urban students (90.9\% vs. 63.2\%). Also among workers, direct contact with livestock was more common in rural compared to urban areas (94.7\% vs. $77.8 \%$ ) (Table 2 ). Diary consumption was common in both rural (98\%) and urban subjects (97.8\%), and there was no statistically significant difference between areas (P value=0.929). The findings of this study showed that, the prevalence rate in winter and spring was higher, and in fall it decreased to minimum levels (Figure 3).

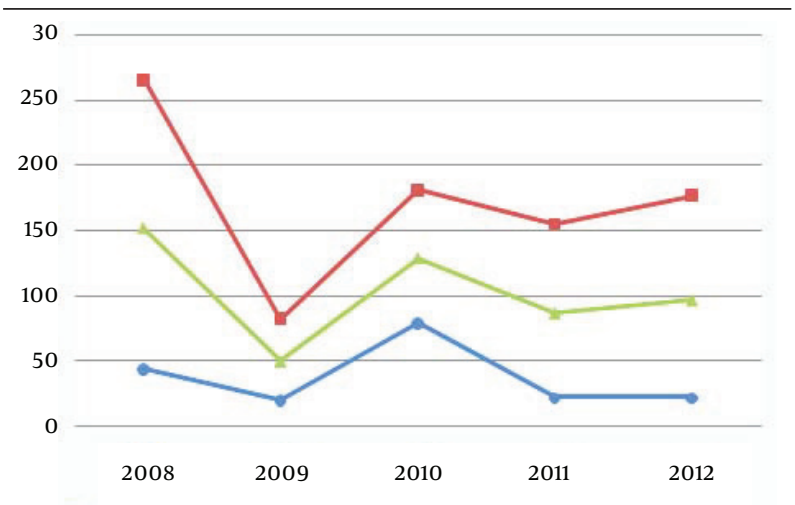

$\rightarrow$ Urban population $-m-$ Rular population $-\_$Total population

Figure 1. Brucellosis Trend of Prevalence Rates per 100000 Individuals in Western Azerbaijan Province; Urban, Rural and Total Populations (20082012)

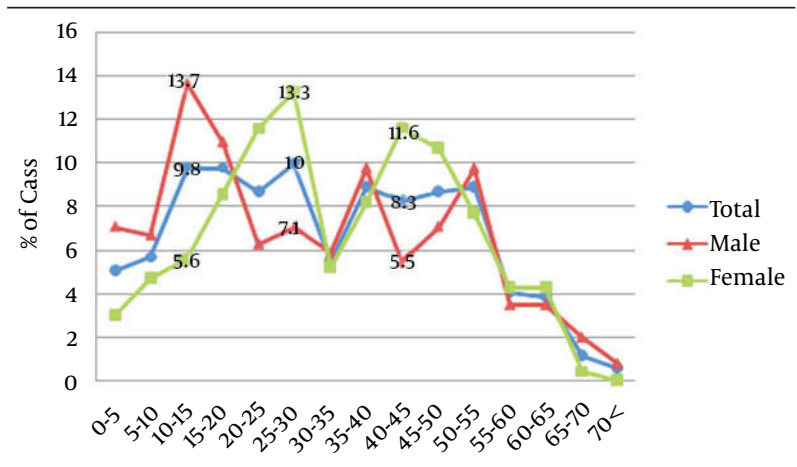

Figure 2. Age Distribution of Cases With Brucellosis as Reported by Public and Private Centers in Western Azerbaijan Province According to Gender (2008-2012) 
Maleki F et al.

Table 1. Occupational Distribution of Cases With Brucellosis Reported by Public and Private Centers in Shahin Dezh

\begin{tabular}{lccc}
\hline Job & \multicolumn{2}{c}{ Area } & \multirow{2}{*}{ Total No, \% } \\
\cline { 2 - 3 } & Rural No, \% & Urban No, \% \\
\hline Housewife & $38(40.9)$ & $156(39.1)$ & $194(39.4)$ \\
Preschool & $4(4.3)$ & $21(5.3)$ & $25(5.1)$ \\
Self employed & $6(6.5)$ & $24(6)$ & $30(6.1)$ \\
Student & $19(20.4)$ & $55(13.8)$ & $74(15)$ \\
Farmer & $2(2.2)$ & $39(9.8)$ & $41(8.3)$ \\
Rancher & $6(6.5)$ & $50(12.5)$ & $56(11.4)$ \\
College student & $2(2.2)$ & $1(0.3)$ & $3(0.6)$ \\
Employee & $1(1.1)$ & $0(0)$ & $1(0.2)$ \\
Shepherd & $0(0)$ & $4(1)$ & $4(0.8)$ \\
\hline Labor & $9(9.7)$ & $19(4.8)$ & $28(5.7)$ \\
\hline Unemployed & $1(1.1)$ & $11(2.8)$ & $12(2.4)$ \\
\hline Others & $5(5.4)$ & $19(4.8)$ & $24(4.9)$ \\
Total & $93(100)$ & $399(100)$ & $492(100)$ \\
\hline
\end{tabular}

Table 2. Distribution of Cases With Brucellosis who had Been in Direct Contact With Livestock Reported by Public and Private Centers of Shahin Dezh

\begin{tabular}{lcccc}
\hline \multirow{2}{*}{ Job } & \multicolumn{3}{c}{ Direct contact with livestock } \\
\cline { 2 - 5 } & \multicolumn{2}{c}{ Urban } & \multicolumn{2}{c}{ Rural } \\
\cline { 2 - 5 } & Yes, \% & No,\% & Yes, \% & No,\% \\
\hline Housewife & $22(57.9)$ & $16(42.1)$ & $143(91.7)$ & $13(8.3)$ \\
Preschool & $2(50)$ & $2(50)$ & $14(66.7)$ & $7(33.3)$ \\
Self employed & $5(83.3)$ & $1(16.7)$ & $21(87.5)$ & $3(12.5)$ \\
Student & $12(63.2)$ & $7(36.8)$ & $50(90.9)$ & $5(9.1)$ \\
Farmer & $2(100)$ & $0(0)$ & $38(97.4)$ & $1(2.6)$ \\
Rancher & $6(100)$ & $0(0)$ & $50(100)$ & $0(0)$ \\
College student & $1(50)$ & $1(50)$ & $1(100)$ & $0(0)$ \\
Employee & $1(100)$ & $0(0)$ & $0(0)$ & $0(0)$ \\
\hline Shepherd & $0(0)$ & $0(0)$ & $4(100)$ & $0(0)$ \\
\hline Labor & $7(77.8)$ & $2(22.2)$ & $18(94.7)$ & $1(5.3)$ \\
\hline Unemployed & $1(100)$ & $0(0)$ & $10(90.9)$ & $1(9.1)$ \\
Others & $5(100)$ & $0(0)$ & $17(89.5)$ & $2(10.5)$ \\
\hline Total & $64(68.8)$ & $29(31.2)$ & $366(91.7)$ & $33(8.3)$ \\
\hline & & & & \\
\hline
\end{tabular}

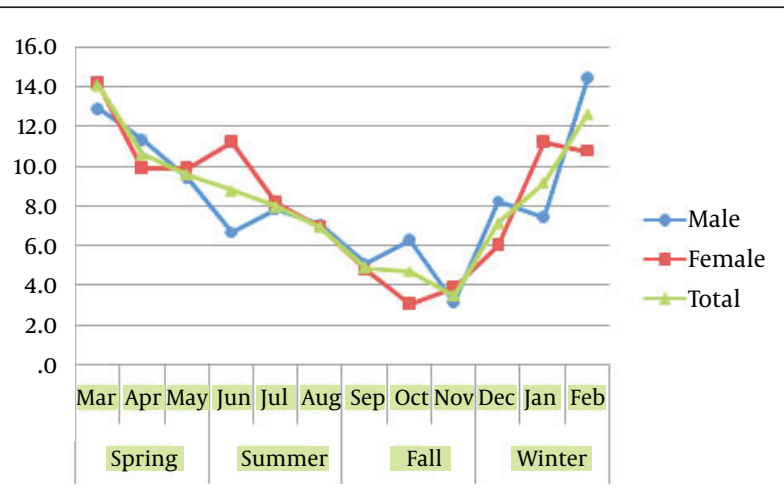

Figure 3. Monthly Distribution of Cases With Brucellosis Reported by Public and Private Centers of Western Azerbaijan Province by Gender (2008-2012)

\section{Discussion}

The Islamic Republic of Iran is located in the Eastern Mediterranean Region (Eastern Mediterranean consists of 22 countries). In this region brucellosis is endemic and the World Health Organization (WHO) has estimated that more than 45000 new cases of brucellosis infections are reported every year from countries of this region (12). Our results indicated that the average prevalence of brucellosis was 102.86/100000 individuals for the five-year period of the study. This finding is consistent with regional rates. A systematic review reported that the prevalence of brucellosis ranged from 0.73 to 149.54 per 100000 individuals per year in Middle Eastern countries. This study also showed that based on sub-national studies, in Iran this rate varies from 0.73 to 141.60 per 100000 individuals per year (13). Unfortunately, there are no precise data about the prevalence of this disease in Iran. A study that conducted by Haghdoost et al. indicated that the annual prevalence of human brucellosis was 141.6 per 100000 inhabitants in Bardsir (a city in south-east of Iran) (10). It can be stated that the prevalence and pattern of brucellosis in Shahin Dezh is similar to national and regional patterns.

It is important to mention that according to our estimates, the prevalence of brucellosis has decreased from 2008 to 2012. This decreasing trend is consistent with other studies from Iran. For example,a study in Isfahan province indicated that the prevalence of brucellosis changed from 17 to 8/100000 individuals, from 2006 to 2009 (14). The high prevalence rate but decreasing trend of brucellosis in this study can be due to the following; 1 ) in the recent years the health surveillance system in Iran has improved. It is reasonable that with the development of the healthcare system, the number of new cases that report to health centers has increased. In other words the high rate of brucellosis prevalence can indicate the success of health programs on this disease in Shahin Dezh.2) The prevalence of brucellosis has declined in the past five years. It appears that promoting veterinary vaccination 
and community education and other interventions have been effective.

Our findings indicate that the prevalence of brucellosis was higher in the younger age groups in comparison to older age groups. This probably implies that younger people have more contact with livestock and animal products, especially in rural areas. Other studies have reported similar results $(14,15)$. Brucellosis occurs in domestic animals and through direct and indirect routes is transmitted to human beings. Some examples of these routes are consumption of unpasteurized milk and dairy products, close contact with infected livestock, their tissues or secretions, herding, lambing, and others $(16,17)$. Regarding the association between brucellosis and the subject's job, our results showed that housewives are the most affected.Transmission through contact can be associated with one's occupation. It is not clear what duties housewives were performing that exposed them to the risk of brucellosis infection; perhaps they were directly involved in activities such as milking cows and tea preparation, during which they were likely to come in direct contact with Brucella contaminated milk. After this group, ranchers were the most affected. Ranchers can be directly exposed to infected animals. According to other studies some specific occupational groups such as farm workers, veterinarians, ranchers, laboratory personnel, nomads, slaughterhouse workers, and meat-packing employees, are at a higher risk (18-21).

The number of cases of brucellosis that were reported by public and private centers in Shahin Dezh, increased from winter to spring and decreased in fall over the fiveyear period of this study. The seasonality of brucellosis can be attributed to the seasonality of parturitions in small ruminants. This seasonality has been reported by other studies, which have found that more than $70 \%$ of the cases of human brucellosis occurred from March to June $(22,23)$. As brucellosis is mainly an occupational disease, the seasonality of this infection is more noticeable. In other words the infection occurs by direct contact with animals during the period of parturitions. This study showed some epidemiological features of human brucellosis in the Western Azarbaijan province, yet as of other cross-sectional studies incidence rate could not be estimated. Longitudinal studies are suggested to determine and monitor the incidence rate of brucellosis and its correlations with other variables. The findings of this study can be used for planning and evaluating interventions by considering risky groups.

\section{Acknowledgements}

We thank all those who helped us conduct this research project.

\section{References}

1. Ariza J, Bosilkovski M, Cascio A, Colmenero JD, Corbel MJ, Falagas ME, et al. Perspectives for the treatment of brucellosis in the 21st century: the Ioannina recommendations. PLoS Med. 2007;4(12).

2. WHO.Brucellosis in humans and animals.: World Health Organization; 2006.

3. Namiduru M, Gungor K, Dikensoy O, Baydar I, Ekinci E, Karaoglan I, et al. Epidemiological, clinical and laboratory features of brucellosis: a prospective evaluation of 120 adult patients. Int J Clin Pract. 2003;57(1):20-4.

4. Roth F, Zinsstag J, Orkhon D, Chimed-Ochir G, Hutton G, Cosivi O et al. Human health benefits from livestock vaccination for brucellosis: case study. Bull World Health Organ. 2003;81(12):867-76.

5. WHO . Browsing by Author Food and Agriculture Organization of the United Nations .: World Health Organization; 1971.

6. Samaha H, Al-Rowaily M, Khoudair RM, Ashour HM. Multicenter study of brucellosis in Egypt. Emerg Infect Dis. 2008;14(12):1916-8.

7. Rabbani Khorasgani M, Esmaeili H, Pourkarim MR, Mankhian AR, Zahraei Salehi T. Anti-brucella antibodies in blood donors in Boushehr, Iran. Comp Clin Path. 2007;17(4):267-9.

8. Pappas G, Papadimitriou P, Akritidis N, Christou L, Tsianos EV The new global map of human brucellosis. Lancet Infect Dis. 2006;6(2):91-9.

9. Alavi SM, Rafiei A, Nikkhooi A. The effect of lifestyle on brucellosis among nomads in Khuzestan province of Iran. Pak J Med Sci. 2007;23(3):358-60.

10. Haghdoost AA, Kawaguchi L, Mirzazadeh A, Rashidi H, Sarafinejad A, Baniasadi AR, et al. Using GIS in Explaining Spatial Distribution of Brucellosis in an Endemic District in Iran. Iran J Public Health . 2007;26(1):27-34.

11. Moradi G, Esmaiel Nasab N, Ghaderi E, Sofi Majidpour M, Salimzadeh H. Brucellosis in Kurdistan Province from 1997 to 2003. Annals Alquds Med. 2006;2(1):32-7.

12. WHO . Fact Sheet N173.: World Health Organization; 1997.

13. Dean AS, Crump L, Greter H, Schelling E, Zinsstag J. Global burden of human brucellosis: a systematic review of disease frequency. PLoS Negl Trop Dis. 2012;6(10).

14. Zeinalian Dastjerdi M, Fadaei Nobari R, Ramazanpour J. Epidemiological features of human brucellosis in central Iran, 2006-2011. Public Health. 2012;126(12):1058-62.

15. Hasanjani Roushan MR, Mohrez M, Smailnejad Gangi SM, Soleimani Amiri MJ, Hajiahmadi M. Epidemiological features and clinical manifestations in 469 adult patients with brucellosis in Babol, Northern Iran. Epidemiol Infect. 2004;132(6):1109-14.

16. Husseini AS, Ramlawi AM. Brucellosis in the West Bank, Palestine. Saudi Med J. 2004;25(11):1640-3.

17. Alballa SR. Epidemiology of human brucellosis in southern Saudi Arabia. J Trop Med Hyg. 1995;98(3):185-9.

18. Tabak F, Hakko E, Mete B, Ozaras R, Mert A, Ozturk R. Is family screening necessary in brucellosis? Infection. 2008;36(6):575-7.

19. Karimi A, Alborzi A, Rasooli M, Kadivar MR, Nateghian AR. Prevalence of antibody to Brucella species in butchers, slaughterers and others. East Mediterr Health J. 2003;9(1-2):178-84.

20. Demiroglu YZ, Turunc T, Aliskan H, Colakoglu S, Arslan H. [Brucellosis: retrospective evaluation of the clinical, laboratory and epidemiological features of 151 cases]. Mikrobiyol Bul. 2007;41(4):51727.

21. Mantur BG, Amarnath SK, Shinde RS. Review of clinical and laboratory features of human brucellosis. Indian J Med Microbiol. 2007;25(3):188-202.

22. Kolar J. Brucellosis in eastern European countries: CRC Press, Boca Raton. In: Edward J. Y. , Michael J. C. editors. Brucellosis: Clinical and Laboratory Aspects.. Florida: Taylor and Francis; 1989. p. 192.

23. Abela B. Epidemiology and control of brucellosis in ruminants from 1986 to 1996 in Malta. Rev Sci Tech. 1999;18(3):648-59. 